\title{
O REENCONTRO DOS SUJEITOS ADULTOS COM A ESCOLA: SIGNIFICADOS E TENSÕES NO ÂMBITO DO PROEJA*
}

\author{
Monica Ribeiro Silva ${ }^{1}$ \\ Ceuli Mariano Jorge ${ }^{2}$
}

\begin{abstract}
RESUMO: $\mathrm{O}$ artigo resulta de um inventário realizado em 18 escolas da cidade e da região metropolitana de Curitiba (PR), que ofertam ensino médio noturno. A análise contemplou 73 alunos do Programa Nacional de Integração da Educação Profissional com a Educação Básica na Modalidade de Educaçáo de Jovens e Adultos (PROEJA). A problemática da pesquisa partiu da identificação do quadro de abandono na última etapa da educação básica e que se vê agravado na especificidade do PROEJA. Os dados obtidos possibilitaram estabelecer o perfil dos alunos conforme idade, sexo, cor e renda mensal, além de evidenciar os motivos que os levaram a retornar aos estudos, a permanecer na escola, o que os desestimulavam e quais motivos os levavam a não desistir. Buscou-se, em face do quadro delineado, uma aproximação dos aspectos que podem levar ao abandono ou à permanência na escola a partir das vozes dos próprios sujeitos do processo.
\end{abstract}

Palavras-chave: PROEJA. Educação profissional técnica de nível médio. Permanência e abandono escolar. Ensino médio.

\section{ADULT SUBJECTS RETURNING TO SCHOOL: MEANINGS AND TENSIONS WITHIN PROEJA}

\begin{abstract}
This paper results from an inventory made at 18 schools in the city and the metropolitan area of Curitiba (PR) that offer evening secondary school. The analysis included 73 students from Programa Nacional de Integração da Educação Profissional com a Educação Básica na Modalidade de Educação de Jovens e Adultos (PROEJA). The research problem was based on the identification of a severe dropout rate in the last stage of basic education which gets worse in PROEJA. The obtained data made it possible to establish students' profile in relation to age, gender, ethnicity and monthly income as well as highlight the reasons that led students to return to school, what motivated them to stay at
\end{abstract}

\footnotetext{
*Este artigo é resultado do Projeto de Pesquisa "Juventude, escola e trabalho", desenvolvido no Observatório do Ensino Médio, com financiamento da Coordenação de Aperfeiçoamento de Pessoal de Nível Superior (CAPES).

${ }^{1}$ Setor de Educação da Universidade Federal do Paraná - Curitiba (PR), Brasil. E-mail: monicars@ufpr.br ${ }^{2}$ Secretaria de Estado da Educaçáo do Paraná; Universidade Federal do Paraná; Rede Estadual de Ensino do Paraná - Curitiba (PR), Brasil. E-mail: ceulimariano@gmail.com DOI: 10.1590/ES0101-73302017137347
} 
school or discourage them from studying, and the reasons that led them not to drop out. Given the outlined context, efforts were made to find an approach of the aspects that may lead students either to drop out or remain at school based on the subjects' statements.

Keywords: PROEJA. Secondary technical school. Retention and dropout. Secondary school.

\section{LE RETOUR DES ADULTES A L'ÉCOLE: LES SIGNIFICATIONS ET LES TENSIONS DE L'EXPERIENCE DANS PROEJA}

RESUME : L'article résulte d'un inventaire réalisé dans 18 écoles de la ville de Curitiba et sa région métropolitaine qui offrent des cours de l'enseignement secondaire le soir. L'analyse comprenait 73 étudiants du PROEJA (sigle en portugais pour le " Programme National d'Intégration entre l'Éducation Professionnelle et l'Éducation Secondaire dans la Modalité d'Éducation des Jeunes et des Adultes »). La problématique de la recherche a été basée sur l'identification d'un cadre d'abandon dans la dernière étape de l'éducation de base qui s'est aggravé dans la spécificité de PROEJA. Les données obtenues ont permis d'établir un profil des élèves en fonction de l'âge, du sexe, de la couleur et du revenu mensuel, en mettant en évidence les raisons qui les ont amenés à retourner à leurs études, ce qui les a motivés à rester à l'école, ce qui les décourageait et les raisons qui les ont conduits à ne pas l'abandonner. On a cherché, étant donné le cadre tracé, un rapprochement des aspects qui peuvent conduire à l'abandon ou à la permanence à l'école à partir des voix des sujets du processus eux-mêmes.

Mots-clés: PROEJA. Formation professionnelle. Enseignement secondaire.

\section{Introdução}

A

investigação de que trata este texto tem origem a partir da identificação de um quadro severo de desistência escolar na última etapa da educaaventado a possibilidade de um contexto de deslocamento de sentido ou de crise de legitimidade da instituição escolar, sobretudo relativos ao ensino médio (DUBET, 1997, 2004; CORREIA; MATOS, 2001; DAYRELL, 2007; KRAWCZYK, 2009). $\mathrm{Na}$ educação profissional técnica de nível médio, esse quadro não é diferente e a busca das razóes da permanência ou da desistência sugere a necessidade de que se procure conhecê-las a partir dos sujeitos diretamente envolvidos nesse processo (DUBET, 1996; SILVA; PELISSARI; STEIMBACH, 2013).

Em face desse quadro e na tentativa de uma aproximação com as razóes que levam a abandonar ou a permanecer na escola, foi realizada uma pesquisa que elegeu como procedimento metodológico ouvir os sujeitos envolvidos a partir da seguinte problemática: "Que sentidos e significados são atribuídos à experiência 
escolar por jovens e adultos que frequentam escolas públicas que ofertam ensino técnico profissional de nível médio? Em que medida esses sentidos e significados se articulam com a opção de abandonar ou de permanecer na escola?".

Para uma aproximação com as respostas possíveis à problemática levantada, foi realizada coleta de dados envolvendo 18 escolas estaduais de Curitiba (PR) e regiáo metropolitana, entre 2011 e 2012, as quais apresentavam a oferta do ensino médio noturno. A pesquisa contou com a participação de 4.143 estudantes nas modalidades: ensino médio integrado, subsequente, Programa Nacional de Integração da Educação Profissional com a Educaçẫo Básica na Modalidade de Educaçấo de Jovens e Adultos (PROEJA), formação de docentes e ensino médio regular. Os estudantes responderam a um questionário com oito questóes fechadas e duas abertas. As respostas a essas questôes permitiram conhecer as características sociodemográficas dos respondentes e os sentidos e significados atribuídos por eles à escola.

No presente texto, será discutida a particularidade dos alunos do universo mencionado e que frequentavam o ensino médio noturno na modalidade PROEJA.

O recorte analisado contemplou a participação de 73 trabalhadores, com mais de 18 anos, que estavam cursando essa modalidade nas escolas pesquisadas, em diferentes estágios do curso, com organização semestral, em seis semestres.

Com a implantação do PROEJA, em 2008, a situação de abandono na última etapa da educaçáo básica foi, desde o início, identificada. No contexto abordado na pesquisa que dá origem a este texto (a rede estadual de ensino do Paraná), observou-se que logo ao final do primeiro semestre de implantação o Programa apresentava uma taxa de abandono em torno de $47 \%$ na totalidade dos cursos. Em 2010, quando as primeiras turmas concluíram, verificou-se um índice em torno de 70\% entre reprovação e abandono, conforme dados obtidos da Secretaria de Estado da Educaçâo do Paraná (SEED/PR).

Para contemplar a abrangência da problemática e dos objetivos propostos, o artigo se estrutura em quatro partes: a primeira, "O contexto do PROEJA", apresenta a modalidade na qual é centrada a análise; a segunda, "Caracterização dos sujeitos da pesquisa", apresenta os alunos do PROEJA que responderam aos questionários, discute e contextualiza suas características; a terceira, "Os sentidos e significados da escola a partir da experiência dos sujeitos", apresenta, discute e analisa os dados quantitativos a partir de uma perspectiva qualitativa, tendo como referencial teórico Dubet (1996, 1997, 2004) e Bourdieu (1996), principalmente; na quarta parte, são apresentadas as consideraçôes finais à análise realizada.

\section{O contexto do PROEJA}

As possibilidades colocadas pelo Decreto $\mathrm{n}^{\circ}$ 5.154/04 para a integração entre a formaçáo profissional e a escolarização oportunizaram a criaçáo do PROEJA, pelos Decretos no 5.478/05 e 5.840/06 (BRASIL, 2004, 2005, 2006). 
Esse Programa foi criado com o intuito de promover uma educação que integrasse a formação geral à profissional para os trabalhadores que precisavam concluir $o$ ensino médio e, ao mesmo tempo, qualificar-se para o trabalho.

Com efeito, a criação do Programa visa preencher o espaço existente para uma formação efetiva voltada aos alunos trabalhadores. Dados da Pesquisa Nacional por Amostra de Domicílios (PNAD), do Instituto Brasileiro de Geografia e Estatística (IBGE), de 2009, apresentados no documento síntese do censo 2010, mostram que o Brasil tem uma população de 57,7 milhóes de pessoas com mais de 18 anos e que não frequentam escola, não possuem ensino fundamental completo e poderiam estar sendo atendidos pela Educação de Jovens e Adultos (EJA).

Com a criação do PROEJA, abriram-se novas possibilidades para o público jovem e adulto, "uma experiência inédita e necessária, pois o trabalho nunca esteve presente nos currículos da EJA" (FRANZOI; SANTOS, 2008, p.70). As matrículas do PROEJA, embora tenham sido em menor quantidade que o esperado (se for considerado o contingente que precisa ser atendido), somaram, em 2007, um total de 9.703 e, em 2012, totalizaram 35.993 alunos no país (INEP, 2007, 2012), seguidas, no entanto, de um grande número de alunos que não permaneceram.

No Paraná, a implantação ocorreu em 2008, em 41 escolas da rede estadual de educação, em diferentes regióes do estado, a partir de um currículo único para cada um dos 12 cursos ofertados. Nesse estado, também foi verificado um crescimento de matrículas, acompanhado pela não permanência de grande número de alunos e dificuldades em consolidar o currículo integrado ${ }^{1}$.

A preocupaçáo diante de novas políticas com o cunho de produzir maior justiça social é a de que elas não podem ser organizadas a partir de práticas compensatórias e paliativas. Discutindo essa questáo, Dubet (2004, p. 540) afirma que "os conceitos de igualdade e de justiça escolar que comandam essas práticas não são tão claros quanto poderia parecer à primeira vista e é importante refletir para avaliar o sentido e o alcance das políticas escolares". Segundo esse autor, embora o desejo de justiça escolar seja inegável, a sua definição é altamente complexa e pode levar a sentidos ambíguos.

Frigotto, Ciavatta e Ramos (2005, p. 1097), analisando as políticas implantadas no Governo Lula, dentre eles as que têm origem no Decreto n ${ }^{\circ} 5.154 / 2004$, afirmam que, apesar das declarações favoráveis à integração entre formação básica e formação específica, "a política de educação profissional processa-se mediante programas focais e contingentes numa travessia marcada por intensos conflitos e no terreno da contradição". Nessa mesma direção, Rummert:

parte do pressuposto de que o campo da educação é fortemente marcado por condicionantes estruturais e que as açóes de governo constituem expressão dos processos de correlaçóes de forças, cujos resultados expressam uma profunda desigualdade de acesso às bases do conhecimento. (RUMMERT, 2007, p. 35). 
Considerando as preocupaçóes acima apontadas, às quais se somam às destas autoras, foi realizada esta pesquisa.

\section{Caracterização dos sujeitos da pesquisa}

Para compreender os sentidos e significados que os sujeitos conferem às suas experiências no processo de formação, o ponto de partida deste trabalho foi a constatação de que os sujeitos da modalidade de ensino em análise — o PROEJA — são alunos trabalhadores, que apresentam um percurso escolar descontínuo, com períodos de interrupçóes marcados por "ausências e retornos constantes, devido a diversas situaçốes que desfavorecem a permanência nos estudos e que são traduzidos equivocadamente como evasão" (BARBOSA, 2009, p, 43). Estabeleceu-se como pergunta inicial: "quem são os sujeitos que estão nos cursos técnicos do PROEJA?". $\mathrm{E}$, assim, a partir do esforço em interpretar as suas respostas, procurou-se elaborar a caracterização.

Dentre os cursos pesquisados nas 18 escolas estaduais do município e da região metropolitana de Curitiba, observou-se um número bastante reduzido de alunos em todas as turmas no momento da coleta de dados. Entre os cursos técnicos ofertados nessas escolas predominou o de Administração; consequentemente, o maior número de alunos que participaram da pesquisa era desse curso, seguido pelos cursos técnicos em Enfermagem, Meio Ambiente, Segurança do Trabalho e Informática (Gráfico 1).

\section{Gráfico 1}

Distribuição dos alunos das escolas estaduais pesquisadas por curso Região Metropolitana de Curitiba (PR), 2011-2012.

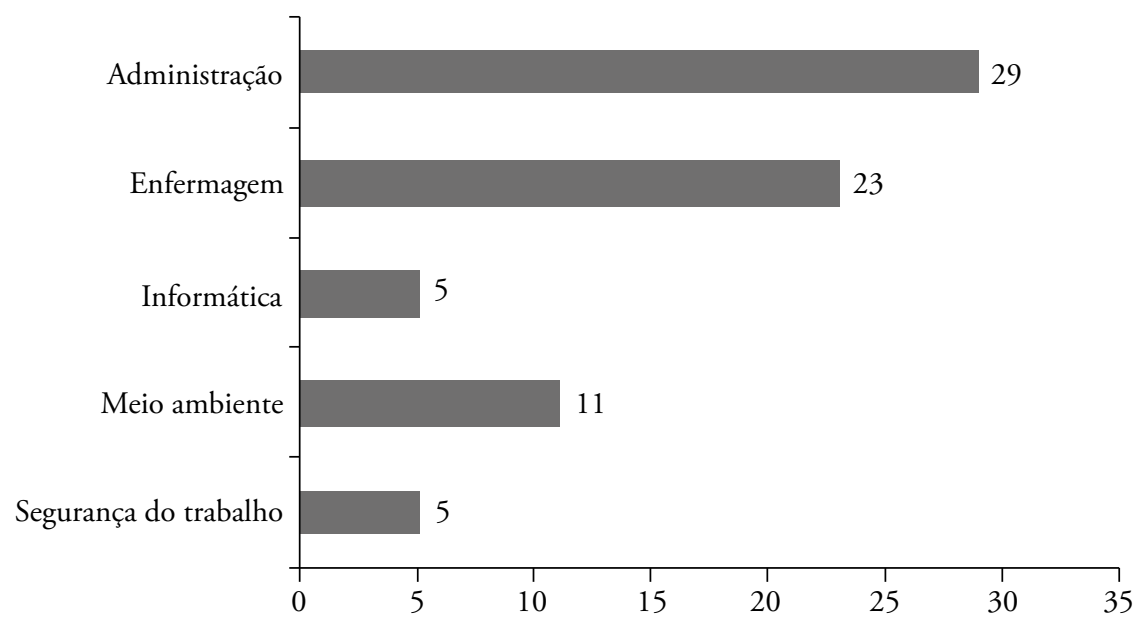


Segundo as equipes diretivas e pedagógicas das escolas participantes, a "evasão" nas turmas do PROEJA era bem acentuada (em torno de 50\%) logo no primeiro semestre, continuando em menor escala até o final do curso. Um fator a destacar, embora não seja diretamente o tema abordado neste texto, é que, no contexto analisado, não se observavam esforços no sentido de oferecer um atendimento diferenciado aos alunos do PROEJA, seja em relação às metodologias ou mesmo às formas de organização e carga horária das turmas, conforme atestam os registros de campos feitos pelas pesquisadoras. Tudo se apresentava tal e qual nas outras modalidades de ensino médio ofertadas, inclusive as mesmas exigências em termos de conteúdo e avaliaçáo, o que poderia ser associado a uma ênfase exagerada ao condicionamento do indivíduo pela estrutura social e escolar (CHARLOT, 2000) em detrimento de outras práticas necessárias à permanência do aluno, relativas às especificidades desses sujeitos, como tempo de estudo e valorização das suas experiências.

A aproximação com dirigentes e coordenadores de cursos, possibilitada pela pesquisa, levou a uma não identificação de autorresponsabilização da escola como instituição que produz a exclusão escolar; as afirmações quanto às razões da desistência remetiam exclusivamente aos alunos, os quais, em seus discursos, como demonstrado na análise das respostas, absorvem essa responsabilidade e a explicam pelos seus próprios limites.

A seguir, é feita uma caracterização geral dos sujeitos que participaram da coleta de dados.

Dos 73 alunos do PROEJA que participaram do levantamento de dados realizado nas 18 escolas, $47 \%$ (ou seja, praticamente a metade dos participantes) pertenciam a uma faixa etária menor do que 30 anos de idade, enquanto que $45 \%$ (quase a mesma proporção) estavam em faixa etária maior que 30 anos (Tabela 1).

\section{Tabela 1}

Faixa etária dos alunos do Programa Nacional de Integração da Educação Profissional com a Educação Básica na Modalidade de Educação de Jovens e Adultos (PROEJA) que participaram da pesquisa - Região Metropolitana de Curitiba (PR), 2011-2012.

\begin{tabular}{c|c}
\hline Idade (anos) & Quantidade \\
\hline Não responderam & 06 \\
\hline De 18 a 24 & 19 \\
\hline De 25 a 30 & 15 \\
\hline De 31 a 40 & 18 \\
\hline Acima de 40 & 15 \\
\hline Total & 73 \\
\hline
\end{tabular}


De uma forma geral, configurou-se um perfil heterogêneo dos alunos com relaçáo à idade, que variou de 18 a 53 anos na totalidade dos cursos pesquisados. Esses dados corroboram o que diz o Documento Base do PROEJA sobre a faixa etária dos sujeitos a serem atendidos: "Formam grupos heterogêneos quanto à faixa etária” (BRASIL, 2007, p. 47). Essa heterogeneidade foi evidenciada igualmente em outras pesquisas publicadas sobre o PROEJA, dentre as quais os estudos de Barros (2010), Oliveira (2011) e Dal Moro (2012). Não obstante, pode-se dizer que no contexto analisado predominava uma faixa etária jovem, se for considerado que mais da metade possuía menos do que 30 anos.

Tal heterogeneidade em relação à faixa etária pode representar, ao mesmo tempo, maior riqueza de experiências a serem vivenciadas, mas, também, pontos divergentes entre os alunos que convivem em uma mesma turma com valores e padrôes comportamentais diferentes. Isso porque os sentidos e significados atribuídos à experiência escolar, nas diferentes fases da vida, são adversos, o que leva ao entendimento de que "a educação de pessoas jovens e adultas não remete apenas a uma questáo de especificidade etária, mas, primordialmente, a uma questão de especificidade cultural" (OLIVEIRA, 1999, p. 1). Essa particularidade da EJA requer maior atenção e preparo dos professores a fim de reforçar os aspectos potencializadores do conhecimento e da harmonia para o grupo.

As mulheres predominaram entre os alunos pesquisados em uma proporção de 46 mulheres a cada 22 homens, embora tenha ocorrido variação dessa proporção entre os cursos. No curso de Enfermagem, por exemplo, todos os participantes eram do sexo feminino; e a maior proporção de mulheres também foi observada em Administração e Meio Ambiente. Por outro lado, nos cursos de Informática e Segurança do Trabalho, havia maior quantidade de homens.

Essa tendência de determinados cursos atraírem mais as mulheres e outros os homens tem origem na própria divisão sexual do trabalho. Tal divisão convenciona os papéis dos homens e das mulheres nos processos de trabalho, configurando profissóes tidas como "femininas" ou "masculinas" a depender das exigências para o exercício da função (HIRATA, 2002).

Apesar de a presença feminina estar hoje em quase todas as áreas consagradas como masculinas, "máximas sexistas permaneceram ou foram sendo criadas, divulgadas, promulgadas ao longo da história com mais ou menos sucesso" (ROSEMBERG, 2012, p. 338) e continuam interferindo em maior ou menor escala nas representaçóes e formas de organizaçóes sociais, principalmente naquelas relacionadas ao trabalho, como se observou na escolha dos cursos.

Com relação à situação de trabalho, constatou-se que todos os entrevistados estavam empregados. A maioria, isto é, 56 alunos informaram receber mais de dois salários mínimos²; dez alunos afirmaram ter renda mensal de um salário mínimo; e cinco alunos disseram ter renda mensal superior a cinco salários mínimos. 
O fato dos alunos estarem inseridos no trabalho por meio de vínculo empregatício, com salário em torno de um a dois salários mínimos, pode ser compreendido nos estudos de Pochmann (2012), pela nova mobilidade na base da pirâmide social brasileira, que teria sido gerada pelo incremento do mercado de trabalho acompanhado pela política de valorização do salário mínimo. Segundo esse autor, a expansão seria principalmente na área de serviços, em funçôes que não requerem qualificações específicas.

Um aspecto interessante que mostra uma situação inversa foi encontrado por Bonow (2010, p. 123), em sua pesquisa com alunos que não permaneceram nos cursos do PROEJA e estavam, em sua maioria, desempregados. Embora na referida pesquisa não tenha sido relacionada a não permanência ao desemprego, essa relação aparece de forma imediata na leitura do texto e nos depoimentos dos alunos, o que pode indicar, dentre outros fatores, a importância de uma estabilidade mínima que assegure a sobrevivência para a permanência dos alunos jovens e adultos na escola.

Com relaçáo à caracterização dos sujeitos, a investigação ainda colheu informaçóes sobre a origem étnico-racial representada pela cor, na qual $62 \%$ dos alunos se autodenominaram de cor branca; $27 \%$, parda; $6 \%$. preta; $1 \%$, amarela; e $4 \%$ não declararam.

Em síntese, foi possível verificar que os alunos do PROEJA que participaram da pesquisa eram a maioria do sexo feminino, de cor branca, em faixa etária entre 18 a 53 anos, estando a maior parte com menos de 30 anos, todos empregados, com renda mensal em torno de dois salários mínimos. Entretanto, ao estabelecer essa caracterização, procurou-se por "igualdades" ou características comuns entre sujeitos com grandes diferenças individuais, seja de personalidade, gosto, modo de pensar, histórico familiar, diferentes modos de exclusão, vulnerabilidades e até mobilidades, caracterizando inumeráveis diferenças. Em resumo, conforme Dubet (2004, p. 4), "marcados por desigualdades sociais que pesaram muito sobre as desigualdades escolares". Esse autor complementa dizendo que essas desigualdades quando não consideradas na escola seguem o "modelo de igualdade de oportunidades meritocrático, que pressupóe, para ser justo, uma oferta escolar perfeitamente igual e objetiva para pessoas com grandes diferenças" (DUBET, 2004, p.4).

\section{Sentidos e significados da experiência no PROEJA a partir do ponto de vista dos sujeitos-alunos}

A reflexão sobre a experiência social se apresenta como capaz de dar um sentido às práticas sociais. Conforme Dubet (1996), esse conceito assenta-se em três lógicas de ação: integração, estratégia e subjetivação/alienação, as quais arti- 
culadas resultam na experiência social. Essa perspectiva pareceu ser a forma mais apropriada para a presente análise. Desse modo, para verificar os sentidos e significados da experiência nos cursos do PROEJA, foram consideradas quatro questôes, respondidas por esses sujeitos: motivaçôes para vir à escola; motivaçóes para não desistir; do que mais gostam e do que menos gostam na escola.

Ao analisar as motivaçóes que trouxeram os 73 sujeitos pesquisados aos cursos do PROEJA, verificou-se que a grande maioria, ou seja, 63 alunos procuraram o curso em busca de formação profissional, o que se completa na alternativa seguinte que foi "para conseguir emprego" (Gráfico 2).

A opção dos alunos pela formação profissional para chegar a uma melhor situação de emprego pode ser compreendida pelas contradiçôes históricas do próprio processo de socialização. Segundo Bourdieu,

a conjugaçấo entre posição social e disposiçóes incorporadas possibilita estabelecer relaçôes entre as dimensôes subjetivas e objetivas dos processos sociais. Esses processos estruturam e são estruturados a partir da articulação e influência do capital cultural e econômico e pelas próprias condiçóes materiais e objetivas da classe social, orientando as açôes independentemente da vontade dos agentes. (BORDIEU, 1996, p. 24)

\section{Gráfico 2}

Motivaçóes dos alunos da rede estadual para buscar os cursos do Programa Nacional de Integração da Educação Profissional com a Educação Básica na Modalidade de Educaçáo de Jovens e Adultos (PROEJA) - Região Metropolitana de Curitiba (PR) , 2011-2012.

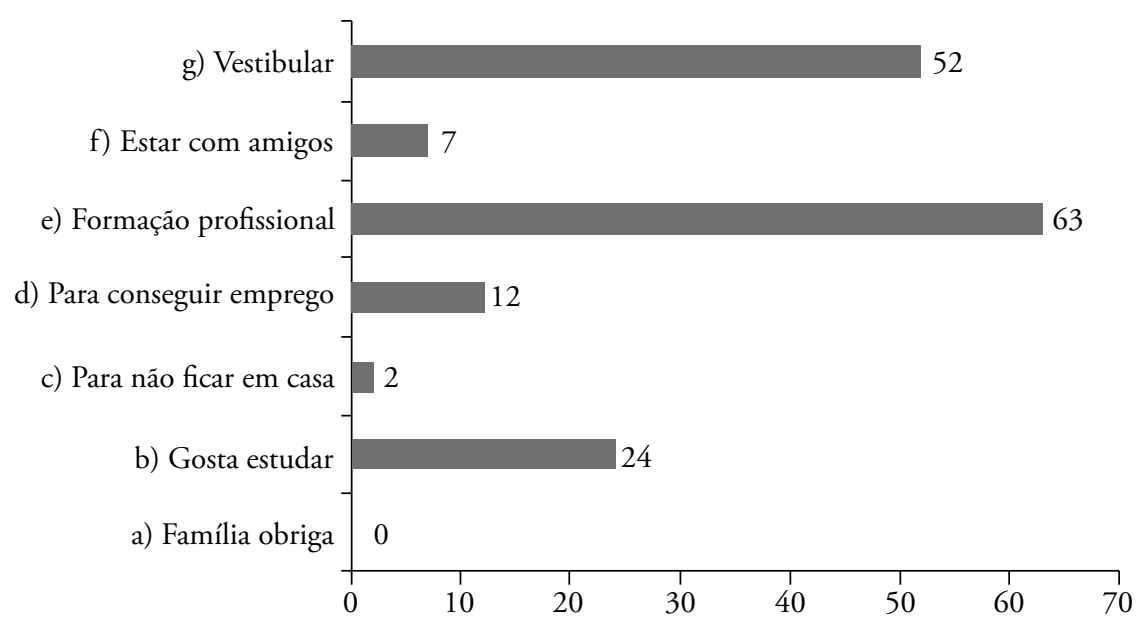


Essa orientação pode ser percebida nas expectativas e trajetórias dos alunos do PROEJA, ou, ainda, na opção imediata pela formação profissional, levados pela necessidade de trabalhar.

A visão da formação profissional para a atuação imediata no trabalho tem origem na Teoria do Capital Humano e está impregnada culturalmente no imaginário dos sujeitos. Com base em Dubet (1996), é possível inferir que isso decorre da lógica de integração, ou seja, a necessidade de sentir-se integrado gera um falso sentido de "pertença" que conduz a uma subordinação consentida e aceita. Em uma lógica estratégica, o sujeito busca a formação para conseguir aquilo que acredita ser o melhor para si e, por isso, empenha-se para estabelecer e manter as regras da concorrência.

A segunda alternativa mais assinalada pelos participantes para a procura dos cursos do PROEJA foi o "vestibular". Essa alternativa associada à terceira, "gosta de estudar", leva a perceber o valor creditado por esses sujeitos no potencial individual de estudo e na capacidade de aprender, ao que, em uma lógica subjetiva, traduz-se em investimento no desenvolvimento próprio e na ruptura de uma barreira social para chegar a um nível de ensino antes distante. Essa perspectiva extrapola, assim, o limite alienante posto pela necessidade de sentir-se "integrado".

Com relação aos motivos para continuar frequentando os cursos, é possível verificar o valor atribuído à escolarização pelos alunos do PROEJA, uma vez que 71 participantes assinalaram a alternativa "concluir os estudos" e 21 alunos assinalaram a alternativa "matérias são interessantes". Destaca-se também, a interferência do bom relacionamento entre o professor e o aluno, ou da "convivência", conforme apontado por eles, na decisão de permanecer no curso (Gráfico 3).

Outro motivo que contribui para a permanência nos cursos do PROEJA, na opiniāo de 19 alunos, foi o convívio com os colegas. Os entrevistados destacaram a importância de pertencer a um grupo constituído entre seus pares, com os mesmos interesses e objetivos e, de uma forma geral, em faixa etária aproximada.

Como afirma Charlot (2000, p. 47), "a experiência escolar é, indissociavelmente, relação consigo, relação com os outros (professores e colegas), relação com o saber". Quando o ambiente escolar é favorável, os alunos constituem redes de socialização, percebem-se como autores de seus estudos, e seus interesses convergem, criando laços e fortalecendo o grupo.

A alternativa "escola de fácil acesso" foi marcada por 14 participantes, indicando que para alunos trabalhadores que vêm direto do trabalho para a escola, o fato de a escola ser próxima à residência representa muitas vezes um fator decisivo para a permanência, principalmente nas grandes cidades onde a distância e o tempo de locomoção são elementos limitantes. 
Sobre a questão do que mais gosta na escola, a alternativa mais assinalada foi o trabalho docente, por 32 participantes. $\mathrm{Na}$ questão anterior, sobre os motivos para não desistir da escola, houve destaque para a convivência com os professores, o que denota a representatividade do trabalho docente para esses alunos e a forma como se identificam com a escola por meio dos professores.

A convivência escolar, destacada por 20 alunos, chama a atenção para a função socializadora da escola, a qual é entendida como um conjunto de relaçóes significativas, porém sem necessidades e interesses específicos. Para esses jovens e adultos que retornaram à escola depois de certo tempo de afastamento, a escola constitui-se em um espaço diferente de convívio, para além das responsabilidades de trabalho e família, mas de novos relacionamentos, de identificação em grupo, lazer e descontraçấo, portanto, com novos significados em sua vida.

Foi destacado por 18 alunos o "preparo, aprendizado e o conhecimento" oferecido pelos cursos, além da "qualidade" destacada por 12 alunos e "disciplinas interessantes" por 11 alunos, como motivos de gostarem mais da escola (Gráfico 4). Embora seja uma pequena proporção dentre os 73 alunos pesquisados, esses motivos indicam a aceitação dos cursos por parte dos alunos, a qual se mostra como fator para a não desistência da escola.

\section{Gráfico 3}

Motivações dos alunos da rede estadual para não desistir dos cursos técnicos do Programa Nacional de Integração da Educação Profissional com a Educação Básica na Modalidade de Educação de Jovens e Adultos (PROEJA) - Região Metropolitana de Curitiba (PR), 2011-2012.

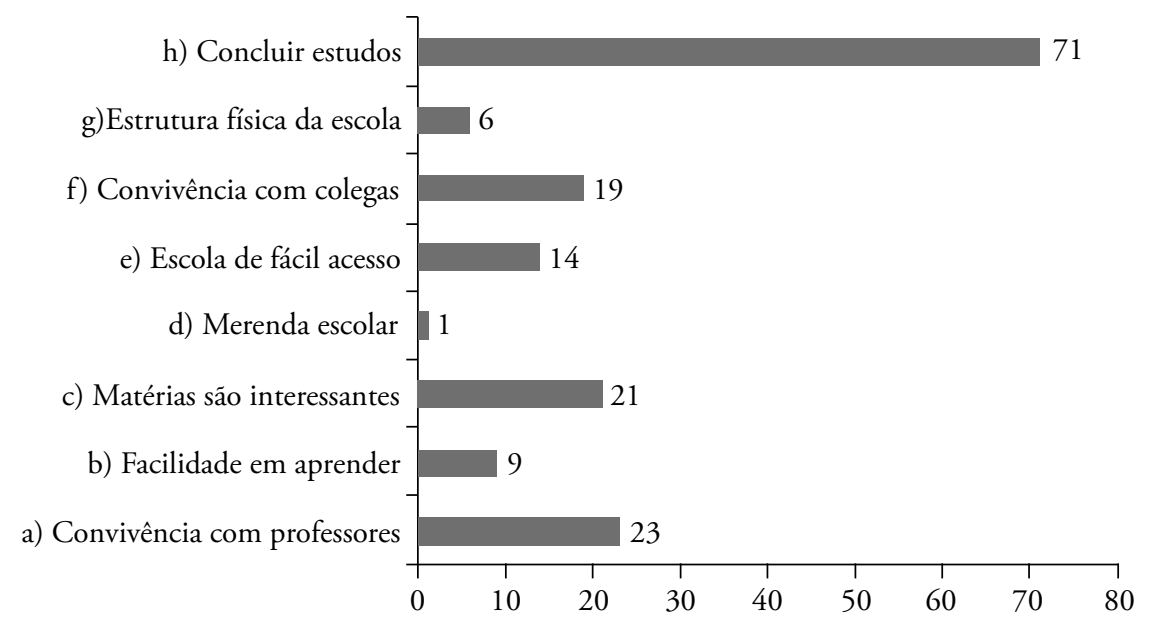


$\mathrm{Na}$ questão "do que menos gosta na escola”, não houve uma alternativa que tivesse grande destaque na opção dos alunos, sendo duas mencionadas por nove entrevistados: "o trabalho docente" e o "desinteresse dos alunos" (Gráfico 5). Essas duas alternativas representam formas negativas na visão desses alunos jovens e adultos, que os afastam da escola, e impóem dificuldades de adaptação ao ambiente escolar, uma vez que encaram os estudos com seriedade e não aceitam um trabalho docente descomprometido, assim como não aceitam o desinteresse de alguns colegas que estariam atrapalhando o ambiente de estudo e o aprendizado, conforme apontaram.

É importante destacar que o trabalho docente foi apontado, na questão anterior, como o principal motivo para gostar da escola e, agora, em menor proporção para não gostar. Pode-se entender que os trabalhos realizados pelos professores são diferenciados, assim como as formas de relacionamentos mantidas com os alunos. Cada professor traz em conjunto com os conhecimentos da sua área/disciplina as suas características pessoais (físicas, psicológicas e comportamentais), que irão influenciar na sua forma de se relacionar com os alunos. Isso está diretamente relacionado, na perspectiva dos alunos, às razóes de abandonar ou permanecer estudando.

\section{Gráfico 4}

Manifestações do que mais gostam na escola os alunos da rede estadual do Programa Nacional de Integração da Educação Profissional com a Educação Básica na Modalidade de Educação de Jovens e Adultos (PROEJA) - Região Metropolitana de Curitiba, Paraná, 2011-2012.

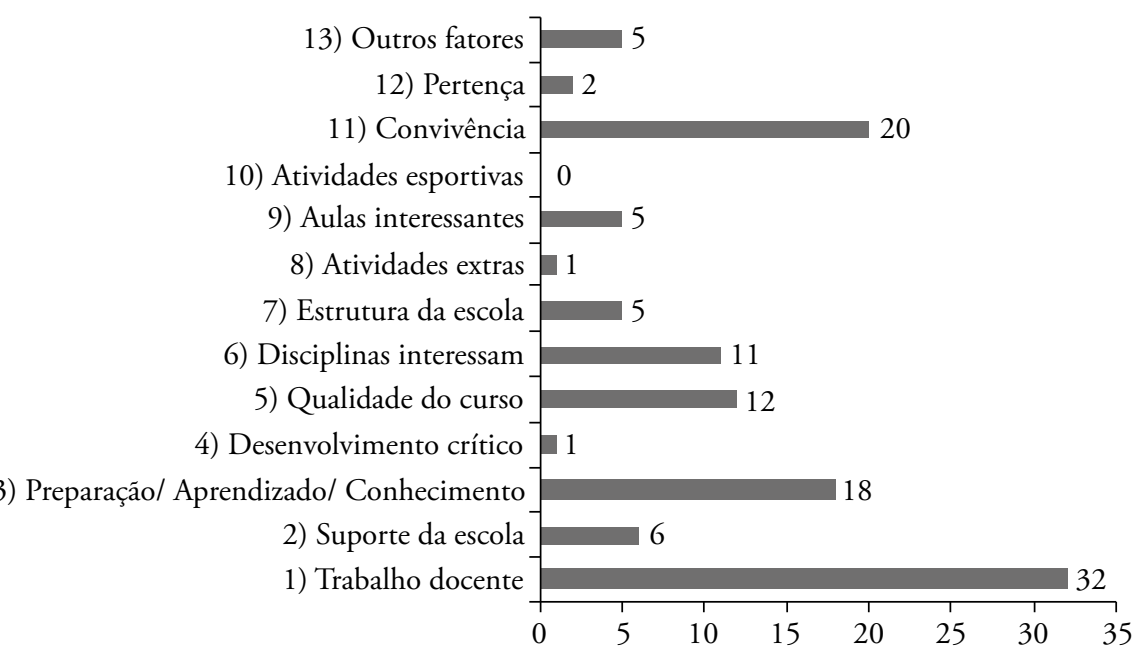


O desinteresse dos alunos e o trabalho docente apresentam uma relação interessante se for considerado que a partir de um (trabalho docente) pode se desencadear o outro (desinteresse dos alunos). Porém, essa relação não é naturalmente percebida; ao contrário, é comum os alunos assumirem o desinteresse como algo próprio e não como uma decorrência do trabalho pedagógico. As alternativas como "desorganização do curso", "sensação de incapacidade", "impotência", "disciplina", "professores" e "estrutura da escola" estáo imbricadas às questóes anteriores e assinalam os pontos nevrálgicos na relação entre os alunos e a escola que desfavorecem o aprendizado e a permanência.

Em síntese, foi possível perceber na experiência dos alunos pesquisados dos cursos do PROEJA um significado inicial diretamente relacionado à formaçáo profissional, porém outros significados em relaçáo à experiência na escola sobressaíram, como: a busca pelo conhecimento; o desejo de continuidade da escolarização em nível superior; o convívio com professores e colegas; a valorização da escola como instituição que traz reconhecimento e distinção social. Foi percebido também que o aluno do PROEJA almeja o aprendizado para seu desenvolvimento próprio, mas quer professores dedicados, boas aulas e colegas interessados em aprender. Essas questóes o fazem gostar da escola. Por outro lado, não aceitam trabalho docente descomprometido, indisciplina e desorganização. Ficam incomoda-

\section{Gráfico 5}

Manifestaçóes do que não gostam na escola da rede estadual os alunos do Programa Nacional de Integração da Educação Profissional com a Educação Básica na Modalidade de Educação de Jovens e Adultos (PROEJA) - Região Metropolitana de Curitiba (PR), 2011-2012.

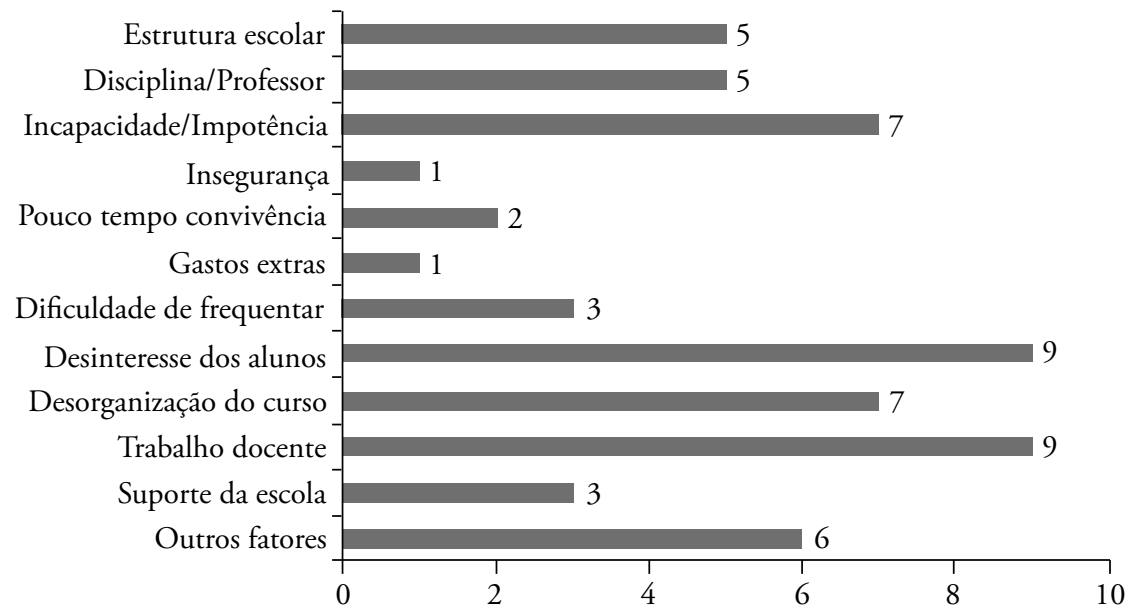


dos com a sensação de impotência diante de determinadas situaçóes vividas no espaço da escola.

\section{Considerações finais}

Havia dois objetivos na pesquisa: o primeiro era caracterizar os alunos do PROEJA das 18 escolas que constituíram o campo empírico; e o segundo era identificar os sentidos e significados da experiência escolar a partir do ponto de vista dos sujeitos-alunos e em que medida esses sentidos e significados estão articulados às razóes para permanecer ou desistir da escola.

Com relação ao primeiro objetivo, a caracterização dos alunos mostrou que a maioria eram mulheres, com idade entre 18 a 53 anos, sendo pouco menos da metade com menos de 30 anos, a maioria de cor branca, empregados, com renda mensal média superior a 2 salários mínimos. No entanto, não dá para afirmar que essas também seriam as características de mais da metade dos alunos que náo permaneceram nos cursos, uma vez que os mesmos náo tiveram participação nesta pesquisa.

Quanto ao segundo objetivo, foi possível identificar que os sentidos e significados da experiência escolar para os alunos do PROEJA estão relacionados a questóes objetivas comuns decorrentes de disposiçóes interiorizadas que os impulsionam a buscar a escolarização e formação profissional para aquisição de emprego.

No entanto, foi percebido que outras questóes de caráter subjetivo configuram significados importantes para esses sujeitos, como, por exemplo: a valorização do conhecimento e da escola; o respeito aos professores e às normas escolares; a convivência com os alunos e os professores; e o desejo expresso de continuidade dos estudos. As formas de organização da escola e das práticas pedagógicas, assim como o relacionamento com os professores e colegas, são fatores que interferem diretamente na opção do aluno em permanecer estudando.

Isso se manifesta tanto em situaçóes nas quais se registraram conquistas de emprego e de novas posiçóes no campo social quanto pelo simples fato de fazer parte de um determinado grupo social, pelo curso. A convivência diária com os colegas e a sociabilidade trazem a sensação de pertencimento a uma situação nova e elevação da autoestima, oportunizando a reconstrução da identidade.

Conclui-se, por fim, que as experiências dos alunos do PROEJA nos cursos são orientadas por disposiçóes efetivas, adquiridas em condiçóes sociais específicas que direcionam as suas trajetórias. Essas disposiçôes efetivas se distanciam daquelas que são realmente almejadas e se colocam como "possíveis" nas teias estruturais que envolvem a vida dos sujeitos alterando os reais sentidos e significados. Assim, os sentidos e significados atribuídos pelos sujeitos do PROEJA 
vão além de uma relação linear entre aluno e escola, são perpassados pelas relações familiares e de trabalho que sofrem os efeitos das condicionantes estruturais.

\section{Notas}

1. A proposta do Programa é que se tratem, em um itinerário formativo único, os conteúdos relativos à formaçáo geral e à formação técnica específica, consolidando uma perspectiva curricular que não dissocia ciência e tecnologia, cultura e trabalho, conforme atesta o documento base que orienta a implantação do PROEJA (BRASIL, 2007).

2. O salário mínimo no Brasil, em 2011, quando foi realizada a pesquisa, era de $\mathrm{R} \$ 688,50$ (seiscentos e oitenta e oito reais e cinquenta centavos).

\section{Referências}

BARBOSA, M.J. Reflexôes de educadoras/es e educandas/os sobre a evasão na escolarização de jovens e adultos. In: PAIVA, J.; BARBOSA, M.J.; WINDYZ, B.F. (Orgs.). Educação de Jovens e Adultos: o que dizem as pesquisas. Recife: Gráfica Jorge Luiz Vasconcelos, 2009.

BARROS, A.B.M. A relação entre os saberes-experiência do trabalho e os saberes escolares, vista por alunos do PROEJA do IFSUL de Sapucaia do Sul. 246 f. Dissertação (Mestrado em Educação)-Programa de Pós-graduação em Educação, Universidade Federal do Rio Grande do Sul, Porto Alegre, 2010.

BONOW, D. A exclusão escolar no PROEJA do IF sul-rio-grandense: representações de estudantes evadidos. 201p. Dissertação (Mestrado em Educação)-Universidade Federal de Pelotas, Pelotas, 2010.

BOURDIEU, P. Razóes práticas: sobre a teoria da ação. Tradução de Mariza Corrêa. Campinas: Papirus, 1996.

BRASIL. Decreto $n^{\circ} 5.154$, de 23 de julho de 2004. Regulamenta o $\$ 2^{\circ}$ do artigo 36 e os artigos 39 a 41 da Lei $\mathrm{n}^{\circ}$ 9.394, de 20 de dezembro de 1996, que estabelece as diretrizes e bases da educação nacional, e dá outras providências.

. Decreto $n^{\circ}$ 5.478, de 24 de junho de 2005. Institui, no âmbito das instituiçóes federais de educação tecnológica, o Programa de Integração da Educação Profissional ao Ensino Médio na Modalidade de Educação de Jovens e Adultos - PROEJA.

. Decreto $n^{\circ}$ 5.840, de 13 de julho de 2006. Institui, no âmbito federal, o Programa Nacional de Integração da Educação Profissional com a Educação Básica na Modalidade de Educação de Jovens e Adultos - PROEJA, e dá outras providências.

Ministério da Educação. Secretaria de Educação Profissional e Tecnológica SETEC. PROEJA: Programa Nacional de Integração da Educação Profissional com a Educação Básica na Modalidade de Educação de Jovens e Adultos. Brasília: SETEC, 2007.

CHARLOT, B. Da relação com o saber: elementos para uma teoria. Porto Alegre: Artes Médicas, 2000. 
CORREIA, J.A.; MATOS, M. Solidôes e solidariedades nos quotidianos dos professores. Porto: Asa, 2001.

DAL MORO, G.A. Do trabalho para a escola: olhares de trabalhadores-estudantes e professores sobre as relaçóes entre o saber da prática e o saber da escola. $176 \mathrm{f}$. Dissertação (Mestrado em Tecnologia) - Programa de Pós-graduação em Tecnologia, Universidade Tecnológica Federal do Paraná, Curitiba, 2012.

DAYRELL, J. A escola "faz" as juventudes? Reflexóes em torno da socialização juvenil. Educação e Sociedade, Campinas, v. 28, n. 100 - Especial, p. 1.105-1.128, out. 2007.

DUBET, F. Sociologia da Experiência. Lisboa: Instituto Piaget, 1996.

Quando sociólogo quer saber o que é ser professor. Entrevista concedida a Angelina Teixeira Peralva e Marilia Pontes Sposito. Tradução de Ines Rosa Bueno. Revista Brasileira de Educação, São Paulo, n. 5, p. 222-231, mai.-ago. 1997.

. O que é uma escola justa? Cadernos de Pesquisa, São Paulo, v. 34, n. 123, p. 539555, set./dez. 2004.

FRANZOI, N.L.; SANTOS, S.V. Mundo do trabalho, leitura, escrita e oralidade: perspectivas da Educação de Jovens e Adultos no Ensino Médio. In: PEREIRA, N.M. et al. Ler e escrever: compromisso no ensino médio. Porto Alegre: UFRGS, 2008. p. 63-72.

FRIGOTTO, G; CIAVATTA, M.; RAMOS, M. A política de educação profissional no Governo Lula: um percurso histórico controvertido. Educaçáo e Sociedade, Campinas, v. 26, n. 92, p. 1087-1113, Especial - out. 2005.

HIRATA, H. Nova Divisão Sexual do Trabalho? Um olhar voltado para a empresa e a sociedade. São Paulo: Boitempo, 2002.

INSTITUTO BRASILEIRO DE GEOGRAFIA E ESTATÍSTICA - IBGE. Censo 2010. Brasil: IBGE, 2010. Disponível em: <http://censo2010.ibge.gov.br/>. Acesso em: 03 set, 2013.

INSTITUTO NACIONAL DE ESTUDOS E PESQUISAS EDUCACIONAIS ANÍSIO TEIXEIRA - INEP. Sinopses Estatísticas da Educação Básica. Brasília: MEC/ INEP. Disponível em: <http://portal.inep.gov.br/basica-censo-escolar-sinopse-sinopse>. Acesso em: 28 ago. 2013.

KRAWCZYK, N. O ensino médio no Brasil. São Paulo: Ação Educativa, 2009.

OLIVEIRA, M.A. O Proeja a partir da concepção de seus educandos- um estudo comparado da realidade do Instituto Federal do Rio Grande do Sul - IFRS/ Campus Sertão e o Campus Bento Gonçalves. 75p. Dissertação (Mestrado em Educaçáo Agrícola). Instituto de Agronomia, Universidade Federal Rural do Rio de Janeiro, Seropédica, 2011.

OLIVEIRA, M,K. Jovens e adultos como sujeitos de conhecimento e aprendizagem. In: XXII Encontro de Pesquisa Educacional Norte e Nordeste - Reuniáo Científica Regional da ANPEd, Caxambu, 1999.

POCHMANN, M. Nova classe média? O trabalho na base da pirâmide social brasileira. São Paulo: Boitempo, 2012. 
ROSEMBERG, F. Mulheres educadas e educação para as mulheres. In: PINSKY, C.; PEDRO, J.M. (Orgs.). Nova história das mulheres no Brasil. São Paulo: Contexto, 2012. p. 333-360.

RUMMERT, S.M. A educação de jovens e adultos trabalhadores brasileiros no século XXI: o "novo" que reitera antiga destituição de direitos. Sísifo: Revista de Ciências da Educação, n. 2, p. 35-50, jan./abr. 2007.

SILVA, M.R.; PELISSARI, L.B.; STEIMBACH, A.A. Juventude, escola e trabalho: permanência e abandono na educação profissional técnica de nível médio. Educação $e$ Pesquisa, São Paulo, v. 39, n. 2, p. 403-417, jun. 2013. Disponível em: <http://www. scielo.br/scielo.php?script=sci arttext\&pid $=$ S1517-97022012005000022\&lng=pt\&nrm =iso>. Acesso em: 10 out. 2013.

Recebido 05 de julho de 2014.

Aprovado 10 de outubro de 2016. 